\title{
APONTAMENTOS SOBRE A MODALIDADE A DISTÂNCIA NO ENSINO SUPERIOR E AAUTORIDADE PEDAGÓGICA NO MUNDO DIGITAL
}

\author{
NOTES ON THE DISTANCE LEARNING IN HIGHER EDUCATION \\ AND PEDAGOGICAL AUTHORITY IN THE DIGITAL WORLD
}

\author{
NOTAS SOBRE LA MODALIDAD A DISTANCIA EN \\ LA EDUCACIÓN SUPERIOR Y LA AUTORIDAD \\ DE LA ENSEÑANZA EN EL MUNDO DIGITAL
}

RoselAine RIPA

Resumo Esse artigo tem o objetivo de trazer apontamentos sobre o crescimento da educação a distância no Ensino Superior no Brasil, por meio de reflexões acerca das relações entre mídia e educação no mundo digital, bem como, as perspectivas de utilização das metodologias da $\mathrm{EaD}$ em outros níveis e sistemas de ensino, a partir da sua implantação como modalidade educacional com a publicação da LDB n ${ }^{\circ}$ 9394/96. Nessa perspectiva, considerando alguns dados relativos à educação a distância no Brasil retirados dos últimos relatórios técnicos do Censo do Ensino Superior, apresentaremos alguns estudos que analisam a implantação da educação a distância e sua relação com a construção de um projeto educacional que utiliza as tecnologias de informação e educação nos processos de ensino e aprendizagem. Em seguida, iremos propor alguns questionamentos sobre a docência no contexto das tecnologias digitais de informação e comunicação, utilizando estudos que destacam reflexões sobre a autoridade pedagógica no mundo digital, tendo como perspectiva a Teoria Crítica da Sociedade.

Palavras-chave: educação a distância. Docência. Mídia. Teoria crítica. Ensino superior.

Abstract This article aims to bring notes about the growth of distance education in Brazil Higher Education, through reflections on the relations between the media and education

Universidade do Estado de Santa Catarina (UDESC), Florianópolis/SC - Brasil. 
in the digital world, as well as, the perspectives of using the methodologies of Distance Learning in other levels and learning systems, since its implementation as an educational modality with the publication of LDB ${ }^{\circ} 9394 / 96$. In this perspective, considering some data about distance education in Brazil taken from the latest Census of Higher Education technical reports, we will present some studies that analyze the implementation of distance education and its relation with the construction of an educational project that uses the technologies of information and education in the teaching and learning processes. Next, we will propose some questions about teaching in the context of digital information and communication technologies, using studies that highlight reflections on pedagogical authority in the digital world, taking as perspective the Society Critical Theory.

Key words: distance education. Teaching. Media. Critical theory. Higher education.

Resumen El objetivo de este artículo es traer notas sobre el crecimiento de la educación a distancia en la Enseñanza Superior en Brasil, a través de reflexiones sobre la relación entre los medios y la educación en el mundo digital, así como las perspectivas para el uso de metodologías de Educación a Distancia en otros niveles y de los sistemas educativos, desde su implementación como modalidad educacional con la publicación de la LDB 9394/96. En esa perspectiva, teniendo en cuenta algunos datos sobre la educación a distancia en Brasil retirados de los últimos informes técnicos del Censo de la Educación Superior, presentaremos algunos estudios que analizan la implementación de la educación a distancia y su relación con la construcción de un proyecto educativo que utiliza las tecnologías de información y educación en los procesos de enseñanza y aprendizaje. Después, vamos a proponer algunos cuestionamientos acerca de la enseñanza en el contexto de las tecnologías de información digital y de la comunicación, utilizando estudios que destacan las reflexiones sobre la autoridad pedagógica en el mundo digital, con la perspectiva de la Teoría Crítica de la Sociedad.

Palabras clave: educación a distancia. Enseñanza. Los medios de comunicación. Teoría crítica. Educación superior.

\section{INTRODUÇÃo}

A Educação a Distância, desde o seu surgimento, relacionado aos cursos por correspondência, é alvo de questionamentos e críticas. No contexto brasileiro, observamos sua utilização cada vez mais frequente não apenas para oferta de cursos abertos, mas principalmente para ampliação de vagas no Ensino Superior e, atualmente, com possibilidades de uso na Educação Básica. Considerada modalidade educacional desde a publicação da LDB $n^{\circ}$ 9394/96, é caracterizada pelo uso cada vez mais intenso das tecnologias de informação e comunicação no processo de ensino-aprendizagem, gerando questionamentos diversos, dentre eles: ao mesmo tempo que se pode reconhecer na $\mathrm{EaD}$ uma possibilidade mais efetiva de ampliação do acesso à educação aos excluídos dos sistemas educacionais, quais são as perdas em termos de qualidade e formação? 
Barreto (2010), Giolo (2010), Mill (2012) e Pucci (2010), dentre outros pesquisadores brasileiros, apontam a importância de realização de estudos e pesquisas acerca da modalidade a distância, de forma a superar um debate nacional sobre a EaD que ainda permanece desestruturado, informal e fragmentado.

Nessa perspectiva e diante da inegável e urgente realização de estudos e discussões sobre a utilização cada vez mais frequente das tecnologias digitais de informação e comunicação na educação, em todas as modalidades, níveis e sistemas de ensino, nossa proposta é contribuir com uma discussão que, parte das especificidades da $\mathrm{EaD}$, mas aponta para questões que afetam a educação relacionadas à autoridade pedagógica no mundo digital.

Sendo assim, na tentativa de trazer elementos para essa discussão, dividimos o artigo em duas partes. Na primeira, apresentaremos informações sobre a educação a distância no contexto brasileiro e sua influência em um projeto de educação ancorado em um paradigma instrumental. Na segunda parte, após uma reflexão sobre a docência na modalidade a distância, discutiremos a autoridade pedagógica no mundo virtual.

\section{EAD No BRASIL E SUA INFLUÊNCIA NA CONSTRUÇão DE UM PROJETO DE EDUCAÇ̃̃o}

Diversos estudos apontam que a crescente demanda por educação e a democratização do acesso à escola têm exigido mudanças na função, na estrutura e nos profissionais que atuam nos diversos níveis, sistemas e modalidades de ensino no Brasil. Inseridos em um mundo cada vez mais digital, essas mudanças incluem a utilização de tecnologias digitais de informação e comunicação nos processos de ensino-aprendizagem, justificadas para conseguirem atingir a atenção dos chamados "nativos digitais" ou para possibilitar a ampliação de vagas no Ensino Superior.

No contexto brasileiro, a EaD torna-se um instrumento que tende a influenciar, de um lado, as metodologias do processo de ensino-aprendizagem com o uso das TICs pelo aluno e/ou pelo professor, e de outro, as políticas de promoção de cursos e implantação de projetos educacionais diversos.

Em diversos países, a EaD está consolidada como uma alternativa para a formação e conta com credibilidade e investimentos em metodologias de ensino e tecnologias para otimizar a interatividade e qualificar o processo de ensino-aprendizagem (VERGARA, 2007). No Brasil, ainda há desconfianças, seja pela tradição dos cursos presencial ou pela qualidade questionável na oferta de determinados projetos pedagógicos. Há pesquisas que apontam o bom desempenho dos formados em cursos a distância e/ou em avaliações externas, como o ENADE, ${ }^{1}$ promovidas pelo Ministério da Educação.

Quando realizada via internet, para implantação de cursos na modalidade a distância, há necessidade de uma ampliação dos agentes/profissionais envolvidos, como os tutores, que são aqueles que teriam o papel de auxiliar o acompanhamento pedagógico das turmas, e as equipes multidisciplinares, compostas por designers instrucionais e gráficos, webde-

Exemplo de notícia veiculada pela internet: "Aluno a distância vai melhor no Enade”, disponível em: http:// www1.folha.uol.com.br/fsp/cotidian/ff1009200701.htm Acesso em 12 dez. 2016. 
signers, gerenciadores de ambientes virtuais de aprendizagem (AVA), diagramadores, analistas de sistemas, dentre outros.

Os entusiastas da EaD destacam o seu potencial no desenvolvimento de um processo de aprendizagem mais autônomo, eficaz e adequado às exigências do mundo atual, mas o conceito de Peters (1973) ainda merece atenção. O autor destaca que a Educação a Distância seria uma forma industrializada de ensinar e aprender, ou seja, um método que se propõe a partilhar conhecimentos, habilidades e atitudes por meio da divisão do trabalho, apoiado em princípios organizacionais, com uso extensivo de meios de comunicação especialmente para a reprodução de materiais técnicos, que têm o objetivo de instruir um grande número de estudantes ao mesmo tempo e enquanto esses materiais durarem. Para o autor, é uma forma industrializada de ensinar e aprender. Décadas se passaram e esses questionamentos continuam relevantes e acabam se estendendo para a educação de uma forma geral e não apenas para a $\mathrm{EaD}$.

Segundo Gomes (2010), não há consenso no Brasil sobre a necessidade da EAD para promover o acesso à educação, apesar das justificativas de práticas pedagógicas que utilizem a EaD para garantir o acesso ao conhecimento, ancorada na flexibilização do tempo e da organização curricular. Ao reconhecer o potencial democrático e, ao mesmo tempo massificador que as TICs possuem, o autor destaca a necessidade de reflexão sobre qual conhecimento está sendo proposto: "um saber que emancipa ou um saber que aliena e escraviza ainda mais?" (GOMES, 2010, p.110).

Como já mencionado neste trabalho, a educação a distância passa a ser considerada uma modalidade a partir da publicação da LDB no 9394/96, conforme artigo 80: "Modalidade educacional na qual a mediação nos processos de ensino e aprendizagem ocorre com a utilização de meios e tecnologias de informação e comunicação, com estudantes e professores desenvolvendo atividades educativas em lugares ou tempos diversos".

A Resolução $\mathrm{n}^{\circ}$ 1, de 11 de março de 2016, estabelece diretrizes e normas nacionais para a oferta de programas e cursos de Educação Superior na modalidade a distância, sem trazer avanços significativos, estabelecendo assim a sua definição:

[...] a educação a distância é caracterizada como modalidade educacional na qual a mediação didático-pedagógica, nos processos de ensino e aprendizagem, ocorre com a utilização de meios e tecnologias de informação e comunicação, com pessoal qualificado, políticas de acesso, acompanhamento e avaliação compatíveis, entre outros, de modo que se propicie, ainda, maior articulação e efetiva interação e complementaridade entre a presencialidade e virtualidade "real", o local e o global, a subjetividade e a participação democrática nos processos de ensino e aprendizagem em rede, envolvendo estudantes e profissionais da educação (professores, tutores e gestores), que desenvolvem atividades educativas em lugares e/ou tempos diversos (BRASIL, 2016)

Uma definição que destaca muitos elementos, porém sem avançar nas definições que poderiam impulsionar a discussão em torno da modalidade e das potencialidades e limites dos processos de ensino e aprendizagem que fazem uso das tecnologias digitais de informação e comunicação. 
O incentivo do Poder Público para o desenvolvimento e a veiculação de programas de EaD, em todos os níveis e modalidades de ensino, como também de educação continuada, estava previsto no Art. 80 da LDB n 9394/96. Mesmo assim, observa-se uma grande lacuna entre a publicação da LDB, os Referenciais de Qualidade para a Educação a Distância publicados em 2003 e o Decreto n ${ }^{\circ}$ 5622/2005, que regulamenta o art. 80 da LDB, estabelecendo as disposições gerais da modalidade $\mathrm{EaD}$, o credenciamento para oferta de cursos e programas, incluindo a oferta de educação de jovens e adultos, educação especial e educação especial na modalidade a distância, da educação profissional, da educação básica e, ainda, programas de pós-graduação. Essa lacuna contribuiu para implantação de cursos sem o devido acompanhamento, controle, critérios e avaliação pelo Ministério da Educação. $\mathrm{O}$ fomento para impulsionar a modalidade a distância nas instituições de ensino superior públicas foi realizado com a criação do Sistema Universidade Aberta do Brasil (UAB), por meio do Decreto $\mathrm{n}^{\circ}$ 5.800/2006.

A UAB é apresentada ${ }^{2}$ como um sistema integrado por universidades públicas, para viabilizar a oferta de cursos de nível superior à população com dificuldade de acesso à formação nesse nível de ensino, utilizando a educação a distância. Seu objetivo é expandir e interiorizar a oferta de cursos e programas de educação superior no país, por meio da $\mathrm{EaD}$ e da parceria dos três níveis governamentais (federal, estadual e municipal). Têm prioridade nesse sistema os professores que atuam na Educação Básica da rede pública, seguidos dos dirigentes, gestores e trabalhadores em Educação Básica dos Estados, municípios e do Distrito Federal.

Ao consultar o mesmo site da Capes/UAB já mencionado na nota 02 , encontramos os seguintes dizeres:

\begin{abstract}
Ao plantar a semente da universidade pública de qualidade em locais distantes e isolados, incentiva o desenvolvimento de municípios com baixos IDH e IDEB. Desse modo, funciona como um eficaz instrumento para a universalização do acesso ao ensino superior e para a requalificação do professor em outras disciplinas, fortalecendo a escola no interior do Brasil, minimizando a concentração de oferta de cursos de graduação nos grandes centros urbanos e evitando o fluxo migratório para as grandes cidades.
\end{abstract}

Zuin (2006) e Mill (2012), dentre outros pesquisadores, reconhecem o mérito dos propósitos da UAB para promover a expansão e interiorização do ensino superior público no Brasil. Porém, esses autores também identificam as dificuldades administrativas e pedagógicas do Sistema UAB, principalmente no que se refere aos profissionais que atuam na função docente (professores e tutores), proletarizando alguns, como os tutores presenciais e a distância, sub-remunerando outros, como os professores conteudistas e das disciplinas.

Apesar do Art. 62 da LDB, $\S 3^{\circ}$, afirmar que a formação inicial de profissionais de magistério daria preferência ao ensino presencial, subsidiariamente fazendo uso de recursos

2 Informações obtidas na apresentação "O que é UAB", disponível em: http://www.capes.gov.br/component/ content/article?id=7836 Acesso em 01 nov. 2016. 
e tecnologias de educação a distância, o Sistema Universidade Aberta do Brasil apresenta como prioridade dos professores da Educação Básica e, com a "requalificação" do professor, o fortalecimento do sistema escolar no interior do Brasil. A semente da universidade pública seria, então, por meio dos cursos oferecidos a distância e as licenciaturas são os cursos mais ofertados.

Ao analisar o último Resumo Técnico: Censo da educação superior (2016), divulgado no site do INEP, que apresenta os dados coletados em 2014, é possível identificar que a oferta da modalidade a distância no ensino superior público é ainda muito reduzida se comparada às instituições privadas. O Censo demonstra a oferta de 1.365 cursos, sendo 43,6\% licenciaturas, 35,1\% tecnológicos e 21,2\% bacharéis. Do total das Instituições de Ensino Superior (IES) que ofereciam cursos superiores a distância, $68,7 \%$ pertenciam à rede privada, com predominância de $48,2 \%$ em cursos tecnológicos. A rede pública era responsável por $48,2 \%$ dos cursos, sendo $21,8 \%$ nas instituições federais, $7,0 \%$ nas estaduais e $2,5 \%$ nas municipais. A maior demanda na rede pública é pelas licenciaturas, com os seguintes dados: $75,5 \%$ nas federais, $80,2 \%$ nas estaduais e $48,5 \%$ nas municipais.

Apesar dos números parecerem pouco significativos, segundo dados dos últimos relatórios técnicos, a Educação a Distância é a modalidade de ensino que teve maior crescimento nos últimos anos, atingindo um aumento de aproximadamente $12 \%$ de matrículas desde 2011, representando quase $16 \%$ do total de ingressantes nesse nível de ensino. Em uma primeira aproximação com esses números, podemos julgar que a EaD tem pouco impacto, principalmente nas IES públicas. Porém, a conclusão do Censo da educação superior 2013: resumo técnico $(2015$, p.18) destaca

Embora a educação a distância corresponda a uma pequena parcela do total de
cursos de graduação, ela atingiu o maior percentual de crescimento, $35,3 \%$,
considerando o período de 2010 a 2013, indicando que está fazendo, cada vez
mais, parte do cotidiano brasileiro. As novas mídias e as novas formas de intera-
ção entre aluno e docente na chamada economia do conhecimento fizeram com
que os cursos ofertados nessa modalidade saltassem para 1.258 no ano de 2013 .

Sendo assim, apesar de um número ainda menor de cursos superiores oferecidos a distância se comparado aos presenciais, não podemos desconsiderar o percentual de crescimento dessa modalidade, justificada pelo potencial de promover a ampliação de matriculados no ensino superior, garantir egressos em áreas com falta de profissionais, interiorizar a oferta e atender a públicos excluídos do ensino presencial, por exemplo, garantir formação às pessoas com problema de mobilidade, aos trabalhadores que não ingressaram no Ensino Superior ao término do Ensino Médio. Mas não é apenas essas questões que estão envolvidas. Nos relatórios técnicos, como na citação, e em outros documentos, o crescimento também é justificado por trazer uma proposta de utilização das novas mídias, em consonância com os ditames da sociedade atual, promovendo novas formas de interação entre professor e aluno. Não há menção às dificuldades de contratação, atuação e desenvolvimento da docência nesses cursos, que apontaremos no próximo tópico. 
Não é apenas no ensino superior que a modalidade a distância está presente. O artigo 32 da LDB no 9394/96, § 4º traz a possibilidade de uso da educação a distância como complementação da aprendizagem ou em situações emergenciais no ensino fundamental. E no contexto brasileiro atual, em que se efetivou um golpe de Estado (LÖWY, 2016), com diversas medidas que estão afetando diretamente o desenvolvimento da educação no país, foi aprovada a Lei $n^{\circ} 13.415 / 2017$, uma conversão da Medida Provisória $n^{\circ}$ 746, de 2016, que altera as Leis n. ${ }^{\circ}$ s 9.394/1996 e 11.494/2007 e o Decreto-Lei n. ${ }^{\circ}$ 236/1967 e revoga a Lei n. $.^{\circ} 11.161 / 2005$, permite, por meio da alteração do Art.36 da LDB:

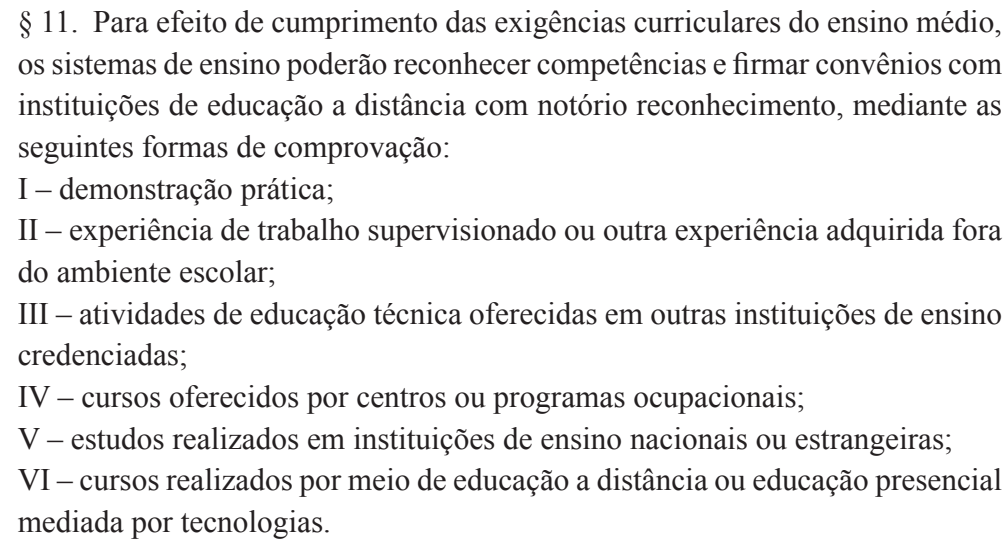

Não faremos aqui uma discussão sobre as redefinições dos objetivos formativos que tais alterações impuseram ao Ensino Médio, apesar da sua importância e urgência. Vamos apenas apontar que no caso específico do parágrafo 11, do Art. 36, tal determinação, realizada sem uma discussão com os profissionais envolvidos e as instituições que possam estabelecer os convênios, é bastante questionável quando menciona "instituições de educação a distância com notório conhecimento" e ao trazer uma equivalência das exigências curriculares com itens que fortalecem a experiência prática, desconsiderando outras dimensões da formação cultural, com ênfase para a mediação das tecnologias.

Souza et. al. 2010 apontam que a expansão da EaD no Brasil revela muito mais do que os avanços de mais uma modalidade educacional, pois apresenta um novo paradigma instrumental para a esfera educacional. Os autores destacam que esse objetivo já estava presente nos documentos da Secretaria de Educação a Distância (SEED), criada em 1995: "[...] levar para a escola pública toda a contribuição que os métodos, técnicas e tecnologias de educação a distância podem prestar à construção de um novo paradigma para a educação brasileira" (SEED, 2012 apud SOUZA et. al., 2010, p. 07). Com as ações e programas que se efetivaram, os autores observam uma mudança de paradigma na esfera educacional que tem concretizado o caráter instrumental na educação brasileira, em todos os níveis e modalidades, apoiada em pressupostos filosóficos pragmáticos, que interferiram na identidade das instituições e dos seus profissionais.

Se retomarmos o Art. 87, da LDB n 9394/96, ao instituir a Década da Educação, novamente a EaD é mencionada para promover cursos aos jovens e adultos insuficiente- 
mente escolarizados, bem como, para realizar programas de capacitação aos professores em exercício. Nessa mesma proposta, observamos as metas 10, 11 e 14 do Plano Nacional de Educação (2011 a 2020), com ênfase para o uso da educação a distância na Educação de Jovens e Adultos, na Educação Profissional Técnica de Nível Médio e na Pós-Graduação Stricto Sensu:

\begin{abstract}
Meta 10 - oferecer, no mínimo, 25\% das matrículas de educação de jovens e adultos na forma integrada à educação profissional nos anos finais do ensino fundamental e no ensino médio e fomentar a integração da educação de jovens e adultos com a educação profissional, em cursos planejados de acordo com as características e especificidades do público da educação de jovens e adultos, inclusive na modalidade de educação a distância;

Meta 11 - duplicar as matrículas da educação profissional técnica de nível médio, assegurando a qualidade da oferta; fomentar a expansão da oferta de educação profissional técnica de nível médio na modalidade de educação a distância, com a finalidade de ampliar a oferta e democratizar o acesso à educação profissional pública e gratuita;

Meta 14 - elevar, gradualmente, o número de matrículas na pós-graduação stricto sensu de modo a atingir a titulação anual de 60 mil mestres e 25 mil doutores e expandir a oferta de cursos de pós-graduação stricto sensu utilizando metodologias, recursos e tecnologias de educação a distância, inclusive por meio do Sistema Universidade Aberta do Brasil (UAB).
\end{abstract}

Uma modalidade que cada vez está sendo indicada para atender a números e metas. Segundo Hermida e Bonfim (2006), a modalidade a distância apresenta contribuições para democratizar a educação brasileira, mas também traz consigo os desafios e problemáticas que merecem atenção e estudos para efetivar sua contribuição para a democratização social do conhecimento. "A educação brasileira necessita de transformações significativas, capazes de atender à demanda cada vez maior de pessoas que, condicionadas a uma intensa jornada de trabalho, precisam de outras alternativas de acesso ao conhecimento" (HERMIDA; BONFIM, 2006, p.177). Nesse contexto, os autores observam que muitas das visões entusiastas da EaD revelam uma posição governamental que legitima ainda mais a hegemonia capitalista, pois embora a EAD possa contribuir para um ensino ampliado justificada por atender a demandas sociais relevantes, apresenta problemas, por exemplo, sua realização por projetos-piloto e programas, descontínuos e sem critérios de avaliação.

Por isso, discutir a EAD não é apenas questionar a utilização das tecnologias da informação e comunicação e pensar nas possibilidades ou limites de promover uma formação a distância no ensino superior, mas, acima de tudo, questionar um paradigma instrumental que vem sendo instituído e imposto no âmbito da educação, alinhado com os ditames da sociedade administrada e voltado para a perpetuação da semiformação, ao mesmo tempo que é camuflado por um discurso da autonomia, interação, adequação às necessidades atuais, modernização, democratização e interiorização. Não queremos afirmar com essas considerações que a educação presencial é garantia de formação e a educação a distância é uma modalidade que a impede, pois o que consideramos importante é retomar os propósi- 
tos da constituição da EaD no contexto brasileiro e as indicações de seu uso em diferentes modalidades, níveis e sistemas de ensino.

\section{A autoridade pedagógica na EAD e seus desdobramentos no contexto ATUAL}

Os resultados parciais da pesquisa "Ser professor(a) na Educação a Distância: "Ser professor (a) na EAD: um estudo sobre o trabalho docente nos cursos de Pedagogia/UAB na Região Sul" revelaram que é necessário pensar as especificidades da docência na EaD.

Para isso, os questionamentos sobre "quem ensina a distância", enfatizados por Belloni (2012, p.85), apontam que os usos das tecnologias digitais de informação e comunicação nos processos de ensino-aprendizagem acabam segmentando o ato de ensinar em múltiplas tarefas, uma das características da modalidade a distância, distribuindo essas tarefas para diferentes profissionais, dentre eles os denominados tutores. ${ }^{3}$

O trabalho docente passa a ser desempenhado de forma fragmentada, envolvendo diversos profissionais além do professor, que muitas vezes assume um papel secundário nesse processo. Mill (2012) discute essas questões e destaca que, na modalidade a distância, a docência é realizada como teletrabalho e organizada como polidocência, realizado em condições precárias, de modo parcelar e de acordo com a lógica capitalista de racionalização, que inclui a flexibilização em termos de espaço e tempo.

(...) O professor não mais terá o prazer de desempenhar o papel principal numa peça que ele escreveu e também dirige, mas deverá saber sair do centro da cena para dar lugar a outros muitos atores - os estudantes - que desempenharão os papéis principais em uma peça que o professor poderá até dirigir, mas que foi escrita por vários outros atores (BELLONI, 2012, p. 88).

A transformação do professor em uma entidade coletiva (BELLONI, 2012), não exercendo mais o principal papel nesse processo, tende a atingir, talvez de forma mais implícita, outras modalidades de educação, principalmente com a introdução das tecnologias da informação e comunicação nas salas de aula.

Adorno (2010), sem deixar de reconhecer a necessidade das reformas escolares, menciona que elas não são capazes de promover, por elas mesmas, contribuições definitivas para a resolução de problemas da esfera educacional, podendo engendrar justamente um efeito inverso, uma vez que poderiam reforçar a crise quando "[...] abrandam as necessárias exigências a serem feitas aos que devem ser educados e porque revelam uma inocente despreocupação diante do poder que a realidade extrapedagógica exerce sobre eles" (ADORNO, 2010, p. 8).

3 No Brasil, os tutores são contratados para apoiar o processo de ensino-aprendizagem, atuando junto a um ou mais docentes no acompanhamento das atividades dos polos de apoio presencial (tutores presenciais) ou nos Ambientes Virtuais de Aprendizagem (tutores a distância). Suas atribuições podem ter variações de acordo com o projeto pedagógico, programa ou contratação. 
Uma das mudanças provocadas pelas reformas escolares, cuja necessidade não se pode colocar em dúvida, como Adorno (2010) destaca, é o descarte da autoridade docente, com a proposta de oferecer maior liberdade ao indivíduo, mesmo que com isso haja uma negação dos pressupostos para o momento de maturação. "As reformas escolares (...) descartaram a antiquada autoridade, mas também enfraqueceram mais ainda a dedicação e o aprofundamento íntimo do espiritual, a que estava vinculada a liberdade; e esta - contrafigura da violência - atrofia-se sem ela, conquanto não caiba reativar opressões por amor à liberdade" (ADORNO, 2010, p.21).

Essa denúncia se apresenta ainda muito atual quando observamos nos discursos, legislações e reformas, que o profissional da educação passa a ser equivalente a qualquer pessoa com "notório saber". Nas alterações da LDB n ${ }^{\circ}$ 9394/96, nos artigos que tratam dos Profissionais da Educação, impostas pela Medida Provisória $n^{\circ}$ 746, de 2016, e efetivadas na Lei ${ }^{\circ} 13.415$, de 2017, encontramos:

profissionais com notório saber reconhecido pelos respectivos sistemas de ensino,
para ministrar conteúdos de áreas afins à sua formação ou experiência profissio-
nal, atestados por titulação específica ou prática de ensino em unidades educacio-
nais da rede pública ou privada ou das corporações privadas em que tenham atua-
do, exclusivamente para atender ao inciso V do caput do art. 36 (BRASIL, 2017).

As imposições da Medida Provisória, $n^{\circ} 746$, de 2016, apesar das diversas manifestações dos estudantes e profissionais da educação, tratam da política de fomento à implementação de escolas de Ensino Médio em Tempo Integral, alterando a LDB no 9.394/96 e a Lei $\mathrm{n}^{\circ}$ 11.494/2007. Na consulta pública, essa medida, em 1 de novembro de 2016, apenas tinha aprovação de $5 \%$ da população.

A escola, na lógica da sociedade administrada, esvaziada de conteúdo, de profissionais, de conhecimento, de reflexão crítica, tende a continuar se apropriando apenas do cotidiano, do imediato, do superficial, do pragmático, do fragmentado. Bastaria, nesse sentido, o "aprender a aprender", que é adquirido na ação do indivíduo em seu cotidiano, de acordo com sua disposição e interesse. O que é divulgado como essencial é o planejamento do próprio sucesso, o estar "ligado" às novidades e adaptar-se ao ritmo e às mudanças do mundo atual. Os profissionais da educação passam a ser substituídos por pessoas com notório saber, pois um dos seus papeis nesse contexto é facilitar aos estudantes o atendimento às exigências produtivas do mercado mundial e o desenvolvimento das habilidades e competências para a atuação profissional imediata.

Adorno (1995) nos ajuda a questionar esse contexto quando indica a sua concepção de educação:

Evidentemente não a assim chamada modelagem de pessoas, porque não temos o direito de modelar pessoas a partir do seu exterior, mas também não a mera transmissão de conhecimentos, cuja característica de coisa morta já foi mais do que destacada, mas a produção de uma consciência verdadeira. Isto seria inclusive da maior exigência política; sua ideia, se é permitido dizer assim, é uma exigência política (ADORNO, 1995, p. 141). 
O autor nos alerta também que é necessário repensar os recursos que são oferecidos para a formação dos profissionais que atuam na educação, pois são pessoas que poderiam contribuir para o desenvolvimento de uma consciência verdadeira. Atualmente, se pensarmos especificamente na modalidade a distância, questionar a atuação dos tutores é relevante. Geralmente são profissionais com formação na área do curso ou ainda em formação, que atuam na $\mathrm{EaD}$ exercendo parte da função docente, mas que não são reconhecidos como professores, sem direitos trabalhistas assegurados, contratados com salários reduzidos ou bolsas, realizando as tarefas designadas pelo professor responsável, dentre elas a correção das atividades proposta nos polos de apoio presencial ou nos Ambientes Virtuais de Aprendizagem.

Outra questão que necessita de maiores estudos se relaciona à autoridade pedagógica na modalidade a distância, como Mashiba (2016) aponta ao indagar o uso de whatsapp, twitter, Snapchat, hangouts e facebook nas salas de aula em geral.

Atualmente, é muito comum ouvir o desabafo dos professores de que enquanto ministram seus conteúdos, os estudantes utilizam a portabilidade para "fugir" da sala de aula. A sensação que possuem é a de que a atenção nunca está voltada para a aula, mesmo quando o uso desses aparelhos é proibido (alguns locais têm leis municipais e estaduais que pró́bem o uso de celular na escola). Nesse contexto, o espaço ocupado pelo modelo de autoridade pedagógica é visto como ameaçado.

Mashiba (2016) destaca que a sensação de perda da autoridade docente, revelada pelos professores que se encontram deslocados por acreditarem que já não exercem a autoridade pedagógica, ou que houve o declínio dela, manifesta-se quando o docente se sente constrangido diante das habilidades tecnológicas dos alunos. A autora aponta que um professor muitas vezes é considerado "tradicional" ao se propor a ensinar conteúdos programáticos com maior fundamentação teórica, negando-se a se submeter ao ritmo ditado pelos alunos ou às aulas show exigidas em muitos sistemas e níveis de ensino.

Diante desse cenário, haveria perda ou transferência da autoridade? Mashiba (2016, p.33) destaca:

Esse momento em que o docente se mostra frágil perante a turma, quer pela falta de domínio teórico, por medo do enfrentamento com os alunos que passam boa parte conectados à tecnologia e já não são motivados a prestar atenção na aula, ou ainda, por influência de discursos que se configuram como o novo canto da sereia, no qual a autoridade é confundida com autoritarismo na defesa da não diretividade, não configura a perda da sua autoridade, apenas abre espaço para que um modelo mais forte de autoridade influencie seus alunos.

Ao recorrer ao texto Personalidade Autoritária, citando o trecho "[...] é a ausência da autoridade a responsável pela adesão dos filhos ao líder que ocupa o lugar da autoridade" (ADORNO e HORKHEIMER, 1956 apud MASHIBA, 2016, p.34), a autora afirma que não há o declínio da autoridade, mas a substituição de um modelo por outro: "O espaço existente para essa autoridade é ocupado por outro modelo - como a tecnologia por meio das redes sociais -, no entanto, ela pode ser substituída pela igreja, família, livro didático, ou ainda, por outra pessoa ou recurso que exerça influência sobre o indivíduo" (MASHIBA, 2016, p. 34). 
A conclusão que a autora destaca é a de que quando novos modelos de autoridade surgem, a tendência é que ocorra a transferência da autoridade pedagógica para outros meios (ou pessoas) e, no caso do professor, a autoridade cede espaço para outras autoridades, incluindo as tecnologias digitais da informação e comunicação. No caso da educação a distância em que a sala de aula se torna virtual e a função docente é fragmentada e exercida por diversos agentes, os recursos tecnologias tendem a ocupar o lugar da autoridade pedagógica.

Para efetivação desse processo, a semiformação passa a ser um dos fatores principais para que a substituição dessa autoridade seja aceita. De acordo com Mashiba (2016), a autoridade pedagógica como modelo precisa ser um modelo "forte", com o qual o sujeito se identifique, ou seja, um modelo de autoridade enfraquecida sequer merece ser seguido ou ainda questionado.

Sendo assim, Mashiba (2016) destaca que estamos vivemos um movimento que tende em direção à fragilidade e à falta de crédito do docente no meio formativo, devido, entre outros motivos, à transferência da autoridade pedagógica.

Se a educação tradicional pode ser criticada por um certo autoritarismo, por desconsiderar a palavra daquele que é educado, a atual, por querer prescindir da autoridade em nome de uma autonomia do aluno, perde a mediação da distância entre sujeito e objeto impedindo a identificação com a autoridade que permite a sua crítica. (CROCHIK, 1998)

Nesse sentido, de acordo com a autora, o professor precisa ter domínio dos conteúdos que apresenta, de forma a relacioná-los com as bases teórico-filosóficas, assumindo o exercício de uma autoridade pedagógica de forma consciente, sem confundi-la com autoritarismo ou falta de diálogo e respeito pelos estudantes. Seria essa autoridade pedagógica consciente que contribuiria para a formação dos estudantes mais autônomos e não a ausência ou fragmentação das funções do professor que deslocam a responsabilidade do processo de aprender única e exclusivamente para os alunos que usam das tecnologias digitais da informação e comunicação como recurso nos processos formativos.

\section{CONSIDERAÇõES FINAIS}

Esse trabalho procurou trazer apontamentos sobre a educação a distância para discutir questões que influenciam a educação na atualidade.

Na primeira parte, ao trazer dados sobre a educação a distância no Brasil, inicialmente demonstrando seu crescimento no Ensino Superior, procuramos caracterizá-la como modalidade educacional, as perspectivas de uso em outros níveis e modalidades de ensino, bem como, sua influência na construção de um paradigma educacional relacionado a introdução das tecnologias digitais de informação e comunicação.

Em seguida, procuramos retomar brevemente como a docência se efetiva na maioria dos modelos pedagógicos adotados pelos cursos a distância, ou seja, de forma compartilhada/pulverizada entre diversos profissionais. Uma temática que precisará ser aprofundada com pesquisas e discussões envolvendo a Teoria Crítica da Sociedade. 


\section{REFERÊNCIAS}

ADORNO, T.W. Teoria da Semiformação. In: PUCCI, B.; ZUIN, A. Á. S.; LASTÓRIA, L. A. C. N. Teoria Crítica e inconformismo: Novas perspectivas de ensino. Tradução de Newton Ramos-de-Oliveira. Campinas, São Paulo: Autores Associados, 2010.

BRASIL. Lei de Diretrizes e Bases da Educação Nacional no 9394/96. Brasília: 1996. BELLONI, Maria Luiza. Educação a distância. $6^{\text {a }}$ ed. Campinas: Autores Associados, 2012.

CENSO da educação superior 2013: resumo técnico. - Brasília: Instituto Nacional de Estudos e Pesquisas Educacionais Anísio Teixeira, 2015.

CROCHÍK, José Leon. Apontamentos sobre o texto Educação após Auschiwtz de T. W. Adorno. In: Educação e Sociedade: revista quadrimestral de Ciência da Educação/CEDES, n. 42, V.II, Campinas: Papirus, 1998.

HERMIDA, Jorge Fernando; BONFIM, Claudia Ramos de Souza. A Educação a Distância: história, concepções e perspectivas. Revista HISTEDBR On-line, Campinas, n. especial, p.166-181, ago, 2006.

LÖWY, Michael. O golpe de Estado de 2016 no Brasil. Disponível em: https://blogdaboitempo.com.br/2016/05/17/michael-lowy-o-golpe-de-estado-de-2016-no-brasil/. Acesso em: 02 jan. 2017.

GOMES, L. R. EAD e a legitimação do saber técnico-científico na educação superior brasileira. SOUZA, D. D. L.; SILVA JUNIOR, J. dos R.; FLORESTA, M. G. S. Educação à distância: diferentes abordagens críticas. São Paulo: Xamã, 2010.

MASHIBA, Glaciane Cristina Xavier. Sociedade do Espetáculo e a transferência da autoridade pedagógica. In: PUCCI, B. et.al.(orgs.). Atualidade da Teoria Crítica na Era Global. São Paulo: Nankim, 2016.

MILL, Daniel. Docência virtual: uma visão crítica. Campinas: Papirus, 2012.

PETERS, O. A Estrutura Didática da Educação a Distância. São Paulo: Olho d’Água, 1973.

RESUMO técnico: Censo da educação superior 2014. Brasília: Instituto Nacional de Estudos e Pesquisas Educacionais Anísio Teixeira, 2016.

SOUZA, D. D. L.; SILVA JUNIOR, J. dos R.; FLORESTA, M. G. S. Educação a distância - muito a pesquisar. In: _ Educação a distância: diferentes abordagens críticas. São Paulo: Xamã, 2010.

VERGARA, Sylvia Constant. Estreitando relacionamentos na educação a distância. Cad. EBAPE.BR, Rio de Janeiro, v. 5, n. spe, p. 01-08, Jan. 2007. Disponível em: http:// 
www.scielo.br/scielo.php?script=sci_arttext\&pid=S1679-39512007000500010\&lng=en\& nrm=iso. Acesso em 20 fev. 2017.

ZUIN, A. A. S. Educação a distância ou educação distante: o programa Universidade Aberta do Brasil, o tutor e o professor virtual. Educação e Sociedade. Campinas. vol. 27, n. 96 Especial, p. 935-954, out. 2006. Disponível em: http://www.cedes.unicamp.br Acesso em: 20 mai 2012.

\section{Dados da Autora}

\section{ROSELAINE RIPA}

Doutora em Educação pela Universidade Federal de São Carlos. Professora adjunta na Universidade do Estado de Santa Catarina. Florianópolis/SC - Brasil. roselaineripa@gmail. com

Submetido em: $30-03-2017$

Aceito em: 27-6-2017 